\title{
Modelo Brasileiro do Ambiente Interagências para Operações na Fronteira
}

\section{Brazilian Model of the Interagency Environment for Border Operations}

Rev. Bras. Est. Def. v. 4, nº 2, jul./dez. 2017, p. 241-262

DOI: $10.26792 /$ RBED.v4n2.2017.74656

ISSN 2358-3932

\section{JOSÉ CARLOS DE ARAÚJO NETO WILSON JOSÉ BARP LUIS FERNANDO CARDOSO E CARDOSO}

\section{INTRODUÇÃO}

O Plano Estratégico de Fronteiras (Brasil, 2011), que ambicionou a união dos entes federais de Defesa, Segurança Pública e Receita Federal, evidenciou-se como o marco legal de orientação das ações de segurança para a região de fronteira no Brasil. Sua finalidade era tentar neutralizar a atuação do crime organizado, reduzir os índices de violência e intensificar a presença do Estado brasileiro na faixa de fronteira. Contudo, um dos problemas dessa iniciativa governamental, se não o principal deles, foi que, das agências militares e civis envolvidas, poucas estavam preparadas ou tentaram estabelecer os meios e as formas de conduzir uma coordenação interinstitucional eficiente.

Se existem apenas duas operações consideradas de ações conjuntas; se o COC [Centro de Operações Conjuntas], fórum central do Plano, restringe-se a apenas uma dessas operações (Ágata); e se os GGI-FRONs [Gabinetes de Gestão Integrada de Fronteiras] não produzem outras ações integradas, é de se inferir que estes têm sido utilizados tão somente para encontros onde são trocadas informações entre os representantes, que muitas vezes não têm poder decisório. Ainda que tenha havido evolução nas aproximações interagências, as

\footnotetext{
José Carlos de Araujo Neto - Mestre em História Comparada pela UFRJ, Mestre em Segurança Pública pela UFPA e Coordenador de Inteligência do Centro Regional do CENSIPAM em Belém.

Wilson José Barp - Doutor em Ciências Sociais pela UNICAMP e Professor da Universidade Federal do Pará.

Luis Fernando Cardoso e Cardoso - Doutor em Antropologia Social pela UFSC e Professor do Programa de Pós-Graduação em Ciência Política da Universidade Federal do Pará.
} 
entrevistas revelam que existem muitas queixas recíprocas e o reconhecimento de que, na prática, o trabalho continua sendo realizado de forma fragmentada, sem maiores avanços rumo à integração (TCU 2015, 54).

O relatório do Tribunal de Contas da União (TCU 2015), que tratou da primeira etapa da auditoria operacional que avaliou as políticas públicas para o fortalecimento da faixa de fronteira, constatou diversas falhas na implementação do Plano Estratégico de Fronteiras (PEF), o qual foi instituído pelo Decreto $n^{\circ}$ 7.496, de 08/06/2011, já revogado. Ao solicitar respostas dos órgãos responsáveis pela sua operacionalização (Forças Armadas, Polícia Federal, Receita Federal, Polícia Rodoviária Federal, entre outros) sobre o modo como desenvolviam ou controlavam as "ações conjuntas" e as “ações de cooperação” e sobre a "integração de ações” estabelecidas no PEF, o TCU constatou o baixo grau de cooperação ou de integração entre tais órgãos. Assim, a discussão sobre a necessidade de soluções em procedimentos interagências no Brasil, para questões tanto de política de segurança pública, quanto para defesa nacional, é de extrema relevância para a sociedade brasileira, apesar de ainda bastante embrionária no ambiente acadêmico.

Em 2016, o TCU desenvolveu a segunda e a terceira etapas da auditoria para avaliar as políticas públicas para o fortalecimento da faixa de fronteira. Quanto à capacidade organizacional, o tribunal verificou que os órgãos responsáveis pela segurança da região apresentavam baixo grau de investimentos e carência de recursos humanos, materiais e financeiros, como, por exemplo, aeronaves, sistemas de comunicação interoperáveis, instalações físicas e cães farejadores. Diante desses e de outros apontamentos, o TCU encaminhou recomendações aos principais gestores das políticas sobre a faixa de fronteira:

Diante desse cenário, seria apropriado recomendar aos coordenadores da política de fronteira (Ministérios da Defesa, Fazenda e Justiça, pelo PEF, e Ministério da Integração Nacional, à frente da CDIF [Comissão Permanente para o Desenvolvimento e Integração da Faixa de Fronteira ]), que promovam maior interação, com o propósito de discutirem a formatação de um modelo de monitoramento e avaliação da política, constituído por processos, procedimentos e meios suficientes (recursos financeiros, pessoas, estrutura etc.), de maneira a se obterem dados confiáveis e relevantes capazes de darem suporte aos relatórios de desempenho da política e à aferição dos resultados esperados (TCU 2016, 10).

Sem condições de ignorar o trabalho do TCU fartamente documentado, o Governo Federal acabou revogando o decreto do PEF e, em seu lugar, 
instituiu o Programa de Proteção Integrada de Fronteiras (PPIF), por meio do Decreto ${ }^{\circ}$ 8.903/2016, mantendo a mesma finalidade do revogado, que é o "fortalecimento da prevenção, do controle, da fiscalização e da repressão aos delitos transfronteiriços" (Brasil 2016, art. $1^{\circ}$ ). A principal revisão adotada na nova política foi a inserção dos órgãos de inteligência por meio do Sistema Brasileiro de Inteligência (Sisbin). Contudo, embora esse sistema apresente alguns avanços na conduta interagências no Brasil, seu grau de eficiência ainda está abaixo das expectativas vislumbradas por estudiosos. Segundo Marco Cepik (2001), a intensa rivalidade entre a Agência Brasileira de Inteligência (Abin) e a Polícia Federal e a pouca agilidade e transparência por parte das unidades de inteligência das polícias militar e civil são fatores que dificultam a conexão entre essas instituições.

De forma introdutória, bastam algumas das muitas facetas relacionadas à segurança da fronteira para mais que justificar a necessidade imperiosa de direcionar estudos e pesquisas para a correção de algumas falhas no processo de cooperação interagências. A inserção do Sisbin no PPIF não parece uma ação na correção de tais falhas, mas tão somente a soma de mais componentes que apresentam a mesma falha estrutural de cooperação interinstitucional.

Dirigentes e servidores foram unânimes em afirmar que o referido sistema [Sistema Brasileiro de Inteligência] pouco influencia o trabalho de informações interagências, haja vista o próprio papel da ABIN, que se dedica principalmente a garantir a segurança da Presidência da República, além de sofrer grandes restrições orçamentárias que repercutem negativamente para a finalidade desejada (TCU 2015, 59).

Os primeiros registros do uso da palavra interagências ocorreram depois da década de 80 do século XX, quando passou a ser mais utilizada nos Estados Unidos e Inglaterra (Raza, 2012). Não é comumente encontrada em documentos públicos no Brasil, sendo mais comum no meio militar. Além disso, o próprio termo agência, designando um órgão governamental dotado de funções e de um plano estratégico de ação, apenas foi formalmente adotado em 1998, por meio da Lei no 9.649. Dessa forma, o termo interagências e a sua consequente expressão cooperação interagências são ainda mais recentes.

A atividade interagências no Brasil é caracterizada por apresentar uma doutrina ainda incipiente, incompleta e de vivência prática militar, sendo um tema muito específico, profundamente influenciado no país pelas doutrinas estadunidenses e raramente tratado em debates acadêmicos. Os militares estadunidenses começaram a empregar o termo operações inte- 
ragências para caracterizar as operações militares, que, por algum motivo, necessitavam da participação de instituições não militares, mas que deveriam manter-se subordinadas à estrutura militar da referida operação. Para normatizar os procedimentos envolvendo interações entre militares e civis nas operações militares dos Estados Unidos, surgiu a Joint Publication 3-O8, ${ }^{1}$ intitulada em 1996 por Interagency, Intergovernmental Organization, and Nongovernmental Organization Coordination during Joint Operations ${ }^{2}$ (Estados Unidos, 1996), que, diante das experiências coletadas em campo, sofreu uma revisão em 2006 e outra em 2011, quando passou a chamar-se Interorganizational Coordination during Joint Operations ${ }^{3}$ (Estados Unidos, 2011). Houve, assim, uma modificação do entendimento do termo interagências, que passou a designar a interação somente entre as agências governamentais militares e civis dos Estados Unidos, excluindo as não governamentais. Mais recentemente, a versão 2016 da Joint Publication 3-08 teve seu nome simplificado para Interorganizational Cooperation ${ }^{4}$ (Estados Unidos, 2016), mantendo o conceito de interagências e dando destaque para a importância maior da conduta de cooperação em relação à conduta de coordenação entre as agências governamentais.

Em meio aos constantes debates que são levantados sobre segurança pública no Brasil, inclusive com o aumento da atenção dispensada a esse tema nos programas de pós-graduação do país, a solução baseada na cooperação interagências parece não estar sendo considerada na amplitude e na complexidade que os desafios sociais exigem. Conforme Souza e Garcia (2014), as operações interagências são estratégias conjuntas por meio das quais diversas instâncias com escopo de ação e corpos burocráticos diferentes propõem procedimentos compartilhados para solucionar problemas de arenas híbridas. Desse modo, e considerando o desenho interorganizacional para a política de segurança da fronteira brasileira, faz-se necessário discutir os mecanismos para coordenar e uniformizar o entendimento interagências e criar um ambiente adequado para elevar o desempenho do trabalho integrado na busca dos resultados desejados.

\section{MATERIAL E MÉTODOS}

Este estudo consiste em identificar e analisar as principais políticas de segurança para a faixa de fronteira brasileira de forma a contribuir para a sugestão de medidas destinadas a estimular e a consolidar uma estrutura de cooperação interagências entre os componentes do Sistema Brasileiro de Inteligência dentro do escopo do Programa de Proteção Integrada das Fronteiras. 
O presente trabalho foi desenvolvido em diferentes estágios. Inicialmente, realizou-se uma pesquisa bibliográfica que possibilitou dar a sustentação teórica para a condução das análises documentais desenvolvidas nesta pesquisa. Com base na síntese do conteúdo teórico coletado, foram selecionadas fontes documentais das quais pudessem ser extraídos dados pertinentes ao tema abordado._Foi usada a grade aberta de análise, na qual foram identificadas as categorias para análise, à medida que foram surgindo, sendo elas reajustadas durante o desenvolvimento da pesquisa, para, enfim, serem estabelecidas as categorias finais. A unidade de análise foi o parágrafo, e a análise foi apoiada em procedimentos interpretativos. A metodologia escolhida para esta pesquisa apresentou algumas dificuldades e limitações em relação à coleta dos dados._Quanto à coleta de dados, o principal óbice foi a dificuldade de acesso aos documentos internos do Ministério da Defesa (MD) e das Forças Armadas que faziam referência ao trabalho interagências e das Operações Ágata.

Os primeiros documentos analisados foram os relatórios de auditoria do Tribunal de Contas da União - TC 014.387/2014-0 e TC 020.053/2015-0 - referentes aos aspectos de governança do conjunto de políticas públicas para o fortalecimento da faixa de fronteira, cujo propósito era aprimorar a atuação governamental nessa região e melhorar o desempenho da Administração Pública, os quais deram origem aos Acórdãos do TCU $\mathrm{n}^{\circ}$ 2252/2015 e $\mathrm{n}^{\mathrm{o}}$ 1995/2016, que também fazem parte do arcabouço documental deste trabalho. Os referidos documentos permitiram verificar a atual conduta dos órgãos responsáveis pela segurança na faixa de fronteira brasileira e, consequentemente, enumerar alguns dos desafios a serem superados para alcançar a ambicionada integração institucional.

A importância desses relatórios como fontes baseia-se na metodologia aplicada pelo TCU para sua elaboração. Em cumprimento de suas próprias normas de auditoria, o TCU encaminhou todas as constatações registradas no relatório aos órgãos envolvidos com a política de fronteira, a fim de que eles emitissem os comentários apropriados, permitindo que fosse exercido, de certa maneira, um direito de resposta.

Em seguida, também foi analisado o único documento formal sobre a atividade interagências no Brasil, a publicação do MD chamada "Operações Interagências MD-33-M-12” (Brasil, 2017). Com isso, foi possível compreender um pouco sobre a cultura organizacional do meio militar e sua visão sobre a atividade interagências.

Como só existiram duas operações, durante a vigência do PEF, consideradas pelo TCU como "ações conjuntas" (TCU 2015, 54) - a Operação Sentinela, no âmbito do Ministério da Justiça, e a Operação Ágata, no âmbito do Ministério da Defesa - e como o Centro de Operações Conjuntas 
(COC) estabelecido pelo PEF restringe-se somente à Ágata, essa operação foi escolhida como um estudo de caso pertinente para auxiliar esta pesquisa, mais especificamente a de número oito, realizada em 2014. Este pesquisador, no exercício do cargo de assessor técnico militar do Centro Gestor e Operacional do Sistema de Proteção da Amazônia - Censipam, e lotado no Centro Regional de Belém, pôde estabelecer a observação direta da conduta e de procedimentos de outras agências do Sisbin e suas relações interinstitucionais ocorridas na etapa da Operação Ágata-8 realizada na faixa de fronteira relativa aos estados do Pará e Amapá.

\section{AMBIENTE INTERAGÊNCIAS NO BRASIL}

A parca doutrina sobre atividades interagências no Brasil resume-se à do Ministério da Defesa. Dentre as publicações atinentes ao assunto, a principal é a MD33-M-12 - Operações Interagências, aprovada pelo Ministro da Defesa por meio de Portaria Normativa. Sua primeira edição, em 2012, estava baseada na doutrina estadunidense já descontinuada de 2006, cuja característica principal era a presença de international organizations, agencies of foreign nations, public and private charitable agencies, and religious organizations, ${ }^{5}$ de acordo com a versão de 2006 da Joint Publication 3-08. Contudo, o Departamento de Defesa dos Estados Unidos, a partir de 2011 , excluiu a participação desses atores das chamadas operações interagências, e atualmente a revisão em vigor é a de 2016. Atualmente, a principal doutrina formal no Brasil sobre atividade interagências, cuja segunda versão revisada foi lançada em 2017, continuou baseada nos conceitos estadunidenses de 2006. Logo no prefácio do documento brasileiro, pode-se encontrar um entendimento sobre o termo pelo Ministério da Defesa:

$O$ termo interagências deriva, então, da parceria e sinergia de esforços envolvendo órgãos governamentais e não governamentais, podendo ser nacionais e/ou internacionais, estruturados para alcançar objetivos políticos e estratégicos de interesse nacional, harmonizando culturas e esforços diversos, em resposta a problemas complexos, adotando ações coerentes e consistentes (BRASIL 2017, 11).

Já no documento análogo estadunidense - Joint Publication 3-O8 -, pode-se ler que "interagency coordination describes the interaction between USG [United States Government] departments and agencies and is a subset of interorganizational cooperation" (Estados Unidos, 2016, I-1). Ou seja, mesmo havendo uma revisão em 2017, o entendimento doutrinário brasileiro manteve-se estagnado, análogo aos conceitos da publicação estadunidense de 2006, sem aproveitar sua evolução que é resultante da 
extensa experiência dos militares dos Estados Unidos em operações interagências ao redor do mundo.

Talvez o fator merecedor de maior atenção no documento brasileiro seja a previsão de sua utilidade somente para os militares, com referências de procedimentos a outros documentos operacionais estritamente de cunho militar. Essa condição pode contribuir para obsolescência prematura do documento, dificultando que seus conceitos possam ser absorvidos por outras parcelas da administração pública federal. O próprio documento define sua finalidade:

Estabelecer os fundamentos doutrinários que orientarão as Forças Armadas no processo de planejamento, preparo e emprego em Operações Conjuntas ( $\mathrm{Op} \mathrm{Cj}$ ) envolvendo a participação de órgãos públicos, organizações não governamentais, empresas privadas, ou agências de outros Poderes, na execução das ações (Brasil, 2017, 13).

Apesar do MD33-M-12 - Operações Interagências reconhecer em seu texto que cada organização é singular, possuindo cultura, filosofia, objetivos, práticas e habilidades próprias e que essa diversidade é que caracteriza a força do processo interagências, conforme observado no item 2.2.2 das "Disposições Gerais", o documento passa a ser contraditório em seu capítulo III, que trata do "Planejamento e Condução das Atividades Interagências”. Neste capítulo, conforme o próprio documento, é descrito as relações interagências e o papel dos atores envolvidos. No item 3.1.4 fica estabelecido que o planejamento da operação interagências segue o previsto em outra publicação do Ministério da Defesa, o MD30-M-0 1 - Doutrina de Operações Conjuntas, no qual é descrita a Sistemática de Planejamento e Emprego Conjunto das Forças Armadas (SisPECFA), que ignora o papel de eventuais elementos de organizações civis.

O conceito de cooperação não exige necessariamente a existência da condição de coordenação ou subordinação, no entanto, a cultura militar, baseada em uma rígida hierarquia desenvolveu o chamado "Princípio da Unidade de Comando”, que se baseia na atribuição da autoridade a uma só pessoa, o Comandante. Apesar de considerar termos como "planejamento integrado" e "emprego coordenado", esse princípio prevê que a obtenção das metas comuns só será possível quando houver "unidade de comando no mais alto escalão e mentalidade militar unificada em todos os níveis" (Brasil, 2015, 228). Esse princípio, de certa forma, impede que os militares entendam e tenham a percepção de que as agências estão em um mesmo nível de igualdade operacional, cada qual dentro de suas atribuições legais e áreas de jurisdição. Dessa forma, para os militares, uma operação interagências deverá ser comandada por um militar. 
Coordenar as atividades dos diversos órgãos governamentais é fundamental para o uso eficiente dos recursos nacionais. Caberá ao Ministério da Defesa, por intermédio do Estado-Maior Conjunto das Forças Armadas (EMCFA), realizar a coordenação interagências no nível estratégico. Esse encargo define o cenário de emprego para os comandantes operacionais e táticos (Brasil 2017, 16).

Observa-se que é imprescindível para os militares, que os mesmos estejam na coordenação de qualquer operação interagências de que estiverem participando. No entanto, essa premissa não está estabelecida em nenhuma norma supra ou interministerial que respalde esse pensamento. Diferentemente, por exemplo, do Sisbin, cujo funcionamento baseado em uma articulação coordenada entre seus partícipes está previsto em um decreto, o qual define a Abin como órgão central do sistema.

Até mesmo o papel da coordenação do PEF fica prejudicado, eis que dois dos três Ministérios responsáveis por tais funções relatam não ter regulamentação para tanto, sendo que o Ministério da Defesa, em aparente equívoco, afirmou existir regulamentação, que consistiria no próprio Decreto $n^{\circ}$ 7.496/2011, que instituiu o PEF, no Plano Estratégico Emprego Conjunto das Forças Armadas (PEECFA)/2a revisão e nas Instruções e diretrizes da Operação Ágata (TCU 2015, 10).

Portanto, diante de auditoria do TCU, os militares justificaram sua posição de coordenadores com base em um documento interno do Ministério da Defesa, sem levarem em conta que coordenar uma operação militar na faixa de fronteira não é o mesmo que coordenar uma operação interagências na faixa de fronteira. Segundo o TCU, ficou claro que no PEF não há definição clara dos papéis e responsabilidades dessas instituições coordenadoras. Também não existe critério para a designação de comando relativo às operações conjuntas ou para os colegiados no gerenciamento das ações. $\mathrm{Na}$ avaliação do tribunal, é necessária a definição de instrumentos que permitam a construção de uma arquitetura interorganizacional eficiente para que as áreas de responsabilidade estejam claras e sob a supervisão de agências públicas situadas na própria fronteira, encarregadas de exercer a liderança.

O Estado-Maior Conjunto das Forças Armadas (EMCFA) argumentou ao TCU que se destina "a coordenar a execução de operações conjuntas e interagências e, portanto, não é um fórum adequado para a participação social” (TCU 2015, 68). Segundo o EMCFA:

[...] essa participação é dificultada pelo caráter técnico da atividade e pelo seu grau de sigilo. Já o Gabinete de Gestão Integrada de Fronteira (GGIF), este, sim, pode e deve contar com a participação de representação da sociedade (TCU 2015, 68). 
Gabriel Marcella (2008) afirma que interagências é um processo que envolve pessoas e organizações complexas, o que, por si só, aponta para a existência de culturas e perspectivas diferentes a respeito da melhor forma de se realizar uma atividade. O processo é político, pois existe um jogo de poder entre indivíduos e instituições. O exercício do poder acaba por ser uma ação de alguns sobre outros, que se dá em momentos específicos, possibilitado pelos enfrentamentos das forças, ou seja, as configurações das relações de força permitem que em momentos distintos alguns exerçam poder sobre outros. Para Foucault (2002), devem-se entender as relações e os mecanismos de poder nessa perspectiva de correlações de força, escapando-se assim da representação jurídico-discursiva.

Como premissa inicial, entende-se o Estado como uma composição de "redes organizacionais, que são estruturas e que se diferenciam na sua capacidade de controlar os recursos internos e externos, tais como fundos, pessoal e suporte político" (Alford; Friedland, 1985, 1). Os organismos de primeiro escalão da administração pública tendem a racionalizar suas práticas por meio da criação de outras unidades burocráticas que, por sua vez, são todas respaldadas por legislações normativas que definem suas atribuições e jurisdições, permitindo que alcancem certo nível de autonomia no desenvolvimento de suas atividades.

Ora, a configuração do extinto PEF - com ausência de hierarquia entre os órgãos que compunham os chamados Gabinetes de Gestão Integrada de Fronteira (GGI-FRON) ou Centro de Operações Conjuntas (COC) - exigia que as tomadas de decisões ocorressem por consenso. Contudo, sem uma definição clara dos papéis de cada um dos integrantes, ainda que favorecesse a interação entre os membros, não garantia uma rotina de ações coordenadas.

No COC [Centro de Operações Conjuntas], a conclusão é ainda mais preocupante, pois $83,3 \%$ dos entrevistados participam eventualmente ou nunca, incluindo-se nesse número todas as Secretarias de Segurança Pública dos Estados, as quais, inclusive, estão impedidas de se juntar aos demais membros daquele fórum por ainda não terem assinado os respectivos acordos de cooperação, nos termos do art. $7^{\circ}$ do Decreto n ${ }^{\circ}$ 7.496/2011 (TCU 2015, 11).

Assim, diante da constatação da dificuldade de participação dos estados no PEF, o TCU recomendou ao Governo Federal que adotasse as providências que entendesse necessárias para "assegurar a representação no Centro de Operações Conjuntos de todas as instituições partícipes das operações" (TCU 2015, 54), o PPIF, em revisão do PEF, extinguiu a estrutura do COC, mantendo os GGI-FRON. Embora a participação nas duas estruturas estivesse condicionada aos acordos de cooperação, o primeiro funcio- 
nava obrigatoriamente em alguma dependência do Ministério da Defesa, normalmente uma organização militar, enquanto o segundo era formado no âmbito estadual, com base em um documento formalizador. O modo como os interesses e as preferências dos atores são articulados, bem como sua pauta de interação, são aspectos que dão relevo às instituições, estruturam o comportamento coletivo, facilitam a capacidade de influência e geram resultados específicos. Elas afetam o grau de poder que qualquer conjunto de atores (dentro ou fora do governo) tem sobre o resultado político, além de influenciarem a definição de seus próprios interesses.

O conjunto dos modelos de alianças estratégicas é vasto e complexo. Compõe-se de vários tipos de associações entre os órgãos, cada um com sua peculiaridade e propósito próprio para o desenvolvimento estratégico das agências participantes. $O$ grau de cooperação entre as agências é diretamente dependente do tipo de atividade em que estão envolvidas. Entre todas as possíveis, a atividade de inteligência deve ser a ação precedente, por proporcionar as informações necessárias para o desenvolvimento da referida missão. A cooperação é uma peça importante do quebra-cabeça da eficiência da difusão de dados, informações e conhecimento de inteligência e será sem dúvida parte integrante de cada operação. Assim, a capacidade profissional dos recursos humanos envolvidos e a implementação de estruturas organizacionais nos níveis central e regional são elementos determinantes dessas atividades. É por meio dessa educação interagências que as Forças e demais agências aperfeiçoarão recursos e tempo para alcançar o estado final desejável.

\section{ESTUDO DE CASO - DOUTRINA MILITAR}

As operações Sentinela, coordenadas pela Polícia Federal, as operações Ágata, coordenadas pelas Forças Armadas, e as operações Fronteira Blindada, coordenadas pela Receita Federal, representam a capacidade de tais órgãos de operacionalizar as diretrizes do PEF, o sentido de trabalho em conjunto. Contudo, o TCU registrou que:

Embora sejam anunciadas como produtos de ações integradas do PEF, pode-se afirmar, com base nas entrevistas e questionários aplicados, que ditas operações não seguem uma ordenação específica de atividades de trabalho coordenado interagências no tempo e no espaço (TCU 2015, 55).

Ademais, somente a Agata apresentou a estrutura do COC estabelecida no PEF. Por essa razão, essa operação é considerada como estudo de caso nesta pesquisa a fim de permitir monitorar os aspectos que dificultam a cooperação interagências. 
Inicialmente, é necessário esclarecer que, com base no artigo 16-A da Lei Complementar $n^{\circ} 97 / 99$, introduzido pela Lei Complementar $n^{\circ}$ 136/2010, as Forças Armadas passaram a atuar, em caráter subsidiário, em ações preventivas e repressivas na faixa de fronteira, com as chamadas Operações Ágata. Não há, contudo, regulamentação dessa atuação, com relação tanto aos procedimentos individuais e conjuntos, quanto aos períodos de intervenção, se contínuos, frequentes ou esporádicos.

As Operações Ágata são coordenadas pelo Estado-Maior Conjunto das Forças Armadas e seu caráter interagências é entendido pelo convite que é estendido aos demais órgãos governamentais para participarem de tal operação sob a condução dos militares. A partir da definição da área onde será executada a operação, sempre haverá um comando militar de área do Exército responsável por aquela jurisdição: as fronteiras dos estados do Amapá e Pará estão sob a jurisdição do Comando Militar do Norte, com sede em Belém; as fronteiras dos estados de Roraima, Amazonas, Rondônia e Acre, sob a jurisdição do Comando Militar da Amazônia, com sede em Manaus; as fronteiras dos estados do Mato Grosso e Mato Grosso do Sul, sob a jurisdição do Comando Militar do Oeste, com sede em Campo Grande; as fronteiras dos estados do Paraná, Santa Catarina e Rio Grande do Sul, sob a jurisdição do Comando Militar do Sul, com sede em Porto Alegre. Em virtude da superioridade hierárquica do Comandante Militar de Arrea (Exército), sobre os Comandantes dos Distritos Navais (Marinha) e os Comandantes Regionais (Aeronáutica), o Exército coordena o planejamento da operação em sua área de jurisdição. Esse planejamento é desenvolvido em conjunto com as demais Forças, adequando as necessidades e disponibilidades dos diversos órgãos envolvidos, que são convidados a participar, reportando-se ao Centro de Operações Conjuntas (COC), que, pelo extinto PEF, deveria funcionar em uma instalação do MD, que normalmente é uma organização militar. Dessa forma, o controle de todos os segmentos da operação - inteligência, relações públicas, logística ou comunicações - ficava sob o poder dos militares.

As agências civis que aceitam o convite para participar das Operações Ágata logo percebem que sua participação será em um nível de subordinação, o que de imediato favorece a desistência de algumas em permanecerem no empreendimento. Ademais, mesmo que a agência civil opte por subordinar-se à coordenação militar ainda surge outro problema, o centro de coordenação civil-militar $\left(\mathrm{C}^{3} \mathrm{M}\right)$. As Operações Ágatas classificadas pelos militares como uma atividade interagências, são planejadas e executadas conforme os manuais do Ministério da Defesa, nos quais se pode encontrar o entendimento sobre o $\mathrm{C}^{3} \mathrm{M}$ : "A organização e atribuições do $\mathrm{C}^{3} \mathrm{M}$ estão descritas no manual MD30-M-01 Doutrina de Operações Conjuntas, $3^{\circ}$ 
volume. Dentro do EMCj [Estado-Maior Conjunto], o $\mathrm{C}^{3} \mathrm{M}$ deve fazer parte da estrutura do D9, sendo flexível no tamanho e na composição" (Brasil 2012, 28).

A estrutura do EMCj, durante as Operações Ágatas, é composta por células temáticas (D2-Inteligência, D6-Comunicações, etc.), de modo que cada célula é composta por um interlocutor militar de cada Força, dando assim um caráter de conjunto. Entre essas células, está a chamada D9, que, conforme publicação do MD, está definida para receber a concentração das agências civis. Como resultado de observação direta em um processo de planejamento de uma Operação Ágata, fica evidenciado como os militares evitam que as agências civis participem das outras células, restrigindo-as fisicamente a permanecerem na D9, impedindo o seu acesso ao compartilhamento de informações em outros campos de atividade como inteligência, estrutura de comunicações ou relações públicas. Logo, não existe ampla transparência na interação entre órgãos civis e militares durante esse processo; há, antes, um filtro militar para aquilo que os interlocutores das agências civis poderão ou não acessar durante o planejamento de determinada atividade interagências coordenada pelos militares. Assim, estabelece-se o primeiro e grande problema do ambiente interagências no Brasil.

Durante a coleta de informações por meio de questionários, o TCU (2016, 13) registrou que o Ministério da Defesa apresentou sua estrutura de gerenciamento de riscos para o PEF e que os demais partícipes do referido Plano afirmaram que esse tipo de estrutura não existia. A explicação para essa divergência entre o Ministério da Defesa e demais órgãos é que o MD não respondeu ao TCU com base na execução do Plano Estratégico de Fronteiras, mas unicamente na sua condução da Operação Ágata, à qual aplica sua metodologia interna de tratamento de riscos.

Nas respostas dadas aos questionários, observam-se discrepâncias significativas: enquanto o Ministério da Defesa alega existir uma estrutura de gerenciamento de riscos para o PEF, os outros dois coordenadores do Plano afirmam o contrário. De fato, as respostas aos questionários apenas corroboram a percepção de que não há uma uniformidade de entendimento entre as agências partícipes, em decorrência de falhas de comunicação e de transparência, acerca da responsabilidade pelo alcance dos resultados consolidados do Plano Estratégico de Fronteiras.

Até a elaboração dos citados relatórios pelo TCU, haviam ocorrido oito versões da Operação Ágata. Portanto, a de número oito aconteceu no ano de 2014. Explica Graça $(2015,13)$ :

O ápice em quantidade de instituições participantes foi atingido na oitava edição - Operação ÁGATA 8 - ocorrida no ano de 2014, a qual contou com a presença de 12 (doze) ministérios e 20 (vinte) agências 
governamentais, além de aglutinar instituições dos 11 (onze) estados localizados na fronteira terrestre brasileira, segundo dados do portal do MD na rede mundial de computadores (internet).

As Forças Armadas fizeram-se presentes na área de fronteira por um breve período, mediante atividades de inteligência, patrulhamento, postos de bloqueio, controle e fiscalização de estradas próximas à linha de fronteira, em sintonia com as ações dos órgãos que já atuam na região, e de ações cívico-sociais que levam atendimento médico, odontológico e hospitalar a comunidades carentes.

Apesar das críticas apontadas com relação ao seu caráter interagências, é necessário registrar que a Operação Ágata tem sido uma ferramenta importante do Estado brasileiro no combate aos crimes transfronteiriços, dentre os quais se destaca o tráfico de drogas. Seus sucessivos êxitos têm angariado a confiança e a simpatia das agências nacionais e internacionais e, também, da sociedade brasileira. Aperfeiçoamentos, principalmente nos níveis de colaboração, necessitam ser inseridos e buscados. Contudo, a Operação Ágata tem contribuído para, no mínimo, abrir um debate promissor sobre atividades interagências no âmbito nacional.

\section{DISCUSSÃO}

Diante do exposto até agora, é possível notar que as dificuldades de interação entre órgãos autônomos é a falta de confiança, e a confiança só é obtida com o tempo. Assim, surge o papel fundamental dos gestores regionais. Aaker $(2001,263)$ define a aliança estratégica como "uma colaboração que potencializa as forças de duas ou mais organizações para que alcancem metas estratégicas”. Explica que, nessas associações, o que está em questão é um compromisso de longo prazo, não se tratando simplesmente de um recurso tático para gerar uma solução de curto prazo para um determinado problema. O autor esclarece que, independentemente da forma específica que assuma, a aliança deve ser gerenciada separadamente, e as pessoas responsáveis por ela precisam ter os incentivos para torná-la bem-sucedida. De forma complementar, Drucker (2001, 192) também afirma que "ordens vindas do alto não funcionam em uma aliança. A melhor maneira é obter o consenso, antes de haver qualquer disputa, a respeito de um árbitro a quem todos os lados conhecem e respeitam e cujo veredito será como final por todos”. Porém, esses ensinamentos dificilmente serão absorvidos pelo ambiente militar em virtude de aspectos singulares já apresentados aqui como o "Princípio da Unidade de Comando" e o estabelecimento em documento do MD (Brasil, 2017) que 
este, por meio do EMCFA deverá realizar a coordenação interagências no nível estratégico.

As formulações antecipadas minimizam os desacordos, porém não possuem o poder de cogitar todas as possibilidades de atritos e desentendimentos de interesse futuros. Talvez o relacionamento nutrido e discutido periodicamente possa contribuir com resultados significativos para a expurgação dos conflitos gerados por falhas de planejamento inicial nas parcerias; entretanto, de forma alguma, podem-se descartar os ganhos potenciais com a criação de diretrizes ou regulamentos que evitem futuros desentendimentos ou que os medeiem quanto aos necessários fins de direito, quando inevitáveis, pois o planejamento é fundamental.

As barreiras corporativistas geradas pela perspectiva de diminuição de influência das instituições estatais envolvidas na implementação da política pública podem afetar o grau de sua eficiência. Grande parte das decisões tomadas no EMCFA, durante a operacionalização de operações interagências, pode afetar aspectos importantes da sociedade, que, em última análise, é sua criadora e mantenedora. Assim, com exceção de deliberações que tratem de situações e dados sensíveis, cujo sigilo seja essencial para garantir o sucesso das operações, não há justificativa para impedir a participação efetiva da sociedade nas decisões referentes às ações que terão impacto na economia e na segurança da população afetada. A transparência, que é um dos requisitos da boa governança, deve ser traduzida em integral conhecimento pela sociedade dos objetivos e consequências previstas das ações dos órgãos por ela criados para manter sua segurança e tranquilidade, até para que a sociedade possa decidir sobre a conveniência e as oportunidades das ações pretendidas. De modo que parece acertado que o PPIF não considere mais a estrutura do COC, que impedia a participação de interlocutores de órgãos que não tivessem formalizado um convênio.

A partir da recomendação do TCU, segundo a qual é necessário encontrar medidas para "estimular a participação, estabelecer clima de credibilidade e confiança mútuas entre os atores e reduzir o potencial de ocorrerem conflitos interagências" (TCU 2015, 55), esta pesquisa incorpora o raciocínio de Robert Axelrold, o qual afirma que a cooperação mútua pode ser promovida 1) incrementando-se a importância do futuro em relação ao presente, 2) modificando-se os retornos atribuídos aos agentes e 3) ensinando-se aos agentes valores e diretrizes que sirvam para promover a cooperação. Com base nesses níveis, cinco formas de promover a cooperação são possíveis: a) ampliar as projeções sobre o futuro; b) criar incentivos e penalizações; c) ensinar os atores a se preocuparem uns com os outros; d) ensinar a reciprocidade; e) melhorar a capacidade de reconhecimento (Axelrold, 2010). 
Outra maneira de promover a cooperação é ensinar as pessoas a se preocuparem com o bem-estar umas das outras. A coexistência de altruísmo e egoísmo, porém, pode fazer com que atores egoístas explorem repetidamente os altruístas. Nessa situação, egoístas precisam ser tratados de modo distinto de forma a controlar o custo do altruísmo. Axelrod (2010) sugere que devemos ser altruístas com todos num primeiro momento, mas retaliar posteriormente quem não responde de forma cooperativa. A reciprocidade passa, então, a ser fundamento da cooperação. Por isso, outra estratégia é ensinar a relevância da reciprocidade, que tem implícito o princípio de sempre cooperar quando o outro também coopera. A desvantagem potencial dessa ação é atrair outros agentes a explorar quem sempre coopera, atingindo também terceiros que dependem dessa interação. Um dos fundamentos da cooperação baseada na reciprocidade é o de não exigir para si mais do que é justo. Axelrod (2010) justifica assim ensinar a prática da reciprocidade aos atores para que haja mais interações mutuamente benéficas. Uma retaliação a um ato não cooperativo na mesma intensidade, porém, pode desencadear um contínuo de retaliações recíprocas. Axelrod (2010) sugere, então, que haja uma única retaliação e em menor intensidade que a primeira ação não colaborativa. Isso ensina ao agente não cooperativo que os demais agentes estão dispostos a impor-lhe custos por não colaborar, mas ao mesmo tempo sinaliza a disposição para perdoar e voltar a cooperar.

A última forma de promoção da cooperação proposta por Axelrod (2010) envolve o aumento da capacidade de identificar os demais atores e as principais características de suas interações passadas. Isso constrói confiança em relação às ações futuras e ajuda a separar com maior precisão os atos não cooperativos e seus respectivos autores. Assim, a cooperação ampla não é rompida, o rompimento dá-se apenas com o ator não cooperativo. $\mathrm{O}$ efeito intertemporal da cooperação repetida é a construção do hábito de cooperar e a instituição da confiança entre os agentes, tirando deles a necessidade do dispendioso cálculo racional em cada interação. Se o agente não cooperativo não puder ser claramente identificado, corre-se o risco de perder o benefício coletivo da habituação e da confiança na cooperação. Logo, a disseminação das capacidades e atribuições específicas de cada agência deve ocorrer periodicamente por meio de seminários regionais, nos quais essas informações podem ser expostas, o que contribui para ajustar a percepção do modo como uma agência enxerga a outra naquela determinada região, além de estabelecer laços sociais entre os indivíduos. A complexidade das questões relativas à faixa de fronteira amazônica leva a ressaltar que existem desafios similares entre as diversas agências operacionais brasileiras no enfrentamento do crime transnacional. O diálogo 
entre as agências em fóruns específicos, portanto, é essencial para a evolução das condutas em campo, além de diminuir o custo operacional, caso haja coordenação de esforços.

A obrigatoriedade do encaminhamento à Abin de todas as cópias de relatórios de inteligência poderia aumentar a capacidade de coleta de informações pelo órgão central, mas tal conduta implicaria uma reestruturação nos procedimentos internos de cada órgão, o que, provavelmente, encontraria resistências nos órgãos de origem e exigiria uma reorganização de pessoal, equipamentos, capacitação e mudanças nas diretivas da Abin. Sendo assim, a ideia de uma efetiva centralização das informações geradas pela comunidade de inteligência parece estar bem distante da realidade brasileira.

As deficiências e vulnerabilidades decorrentes da falta de conhecimento das condutas e dos procedimentos básicos para órgãos e agentes públicos da comunidade de inteligência devem ser atenuadas a partir de capacitações periódicas oferecidas pelas superintendências da Abin em todo o território nacional. Além do estímulo ao entrosamento e à cooperação entre os agentes públicos, os cursos periódicos ministrados pelas superintendências da Abin poderiam garantir o estabelecimento de uma cultura de inteligência para além do Sisbin, alcançando outros entes da Administração Pública.

Bressan (2002) considera a perda de continuidade consequente das ocasionais reorganizações das estruturas responsáveis pela operacionalização das políticas públicas como uma causa para alguns fracassos de desenvolvimento dessas políticas. Nesse contexto, uma das dificuldades para o estabelecimento da cooperação é a designação dos interlocutores, cuja mudança não contribui para a construção da confiança interinstitucional.

Um profissional interagências precisa saber qual é a contribuição de cada órgão participante por meio dos diálogos desenvolvidos em seminários técnico-profissionais. Deve ter a capacidade de tomar medidas adequadas, efetivas e tempestivas na ocorrência de eventos capazes de afetar o alcance dos objetivos programados para o fortalecimento da fronteira.

Os militares são particularmente aptos a exigir que seus membros de serviço recebam uma série de cursos educacionais sequenciais e progressivos ao longo de sua carreira militar. Outras agências governamentais não têm os orçamentos para apoiar esse nível de atividade educacional. Uma vez que o sistema escolar militar está bem desenvolvido e com recursos, talvez eles possam aproveitar as oportunidades educacionais oferecidas pelos serviços militares.

Como resultado de observação direta, a primeira dificuldade enfrentada pelo militar que é designado para atuar em um ambiente interagências é a falta de atribuições bem definidas em normas para os atores envolvidos. Essa condição força o militar a adotar condutas as quais já são familiares, 
e que por serem oriundas das regras militares, em algumas ocasiões, são consideradas inapropriadas por agentes civis. No entanto, este trabalho mostra que o ambiente interagências é uma realidade cultural diferenciada e atípica, sem precedentes na administração pública. Normalmente, o perfil profissional do militar é caracterizado pela hierarquia inflexível, com cumprimento irrestrito das ordens recebidas. Já em um contexto interagências não há uma cadeia de comando única e distinta, mas um aglomerado de órgãos independentes usando o mesmo caminho, ao mesmo tempo, mas todos indo para destinos diferentes, algo que diverge do paradigma institucional militar.

A eficiência de um sistema cooperativo depende diretamente da amplitude de sua composição e da eficácia dos procedimentos de troca de informações. É um sistema que precisa estruturar-se com base em referências colaboracionistas - e não integracionistas - entre seus componentes. Um sistema cooperativo não pode adquirir constância e estabilidade sem uma troca frequente e coordenada de informações; logo, os órgãos componentes devem facilitar encontros regulares para que o fluxo informacional sobre determinado objeto seja impulsionado.

A interdependência de recursos é baseada em uma organização de certas capacidades que uma outra organização não tem. Esse apoio mútuo inclui recursos como pessoal, logística, instrução e comunicação e estabelece um quadro para a cooperação. Essa interdependência pode desenvolver-se ao longo do tempo e levar a uma forma de cooperação interinstitucional verdadeira. Trabalhar em conjunto para permitir que os objetivos comuns sejam alcançados cria uma sinergia que aumenta com cada operação.

As operações interagências devem ser empreendimentos cooperativos baseados no compromisso de cada integrante dos órgãos partícipes de alcançar os objetivos previamente estabelecidos nas reuniões de planejamento. Com efeito, doutrinas gerais de colaboração interagências não são capazes, por si sós, de superar vícios institucionais que se desenvolvem a partir de normas jurisdicionais e operacionais próprias.

Enquanto houver melhorias claramente específicas a serem feitas nos atuais procedimentos de planejamento e de execução, resolvendo desafios interinstitucionais no nível mais alto da administração pública federal, o canal direto entre as representações regionais dos diversos órgãos federais pode ser a verdadeira chave para a resolução desses mesmos desafios no nível mais específico de enfrentamento dos ilícitos na faixa de fronteira. 


\section{CONCLUSÕES}

As políticas federais para a região de fronteira compõem um universo complexo, no qual há muitos órgãos envolvidos, cada um com diretrizes próprias e múltiplas atribuições em diversas linhas de ação. As evidências demonstram que os domínios institucionais são preponderantemente autônomos para a realização das atividades de controle da fronteira.

A criação de regras obrigatórias de compartilhamento de informações e recursos materiais interagências pode estabelecer o respaldo normativo para determinadas ações. Não basta, porém, estabelecer um conjunto de arranjos formais para promover a cooperação e assegurar que as ações individuais não sejam contraditórias. Para o aproveitamento das múltiplas capacidades das agências, é necessária uma unidade de esforços que se reforcem mutuamente, em constante sinergia.

Alcançar o consenso é uma meta audaciosa que precisa existir em um ambiente interagências, pois se trata de uma opinião coletiva. Buscar o consenso é, provavelmente, o aspecto mais importante para se alcançar a cooperação interagências. Por isso, é preciso privilegiar os canais de interlocução entre as representações regionais das agências, como seminários sobre as atividades dos órgãos, cursos para disseminação das capacidades técnicas dos órgãos, reuniões periódicas de trabalho sobre determinado tema, para compartilhamento e atualização de informações.

Uma infraestrutura de capacitação interagências, apoiada por espaços em órgãos e agências federais, pode configurar-se como um dos principais alicerces para o desenvolvimento de uma melhor cooperação interagência e, consequentemente, para uma maior eficiência na execução das atividades de inteligência. Deve haver uma doutrina de referência, amplitude na capacitação de pessoal, treinamento rigoroso e avaliação focalizada. $\mathrm{Na}$ verdade, os resultados das avaliações devem realimentar o sistema para o refinamento da doutrina, repetindo-se esse ciclo ao longo do tempo. É tempo de todo o governo brasileiro considerar a capacitação interagências de forma mais realista, aproveitando a infraestrutura já existente, pois a segurança do Brasil pode depender disso.

\section{REFERÊNCIAS}

Aaker, David Allen. 2001. Administração Estratégica de Mercado. Porto Alegre: Bookman.

Alford, Robert R.; Friedland, Roger. 1985. Powers of Theory: Capitalism, the State, and Democracy. Cambridge: Cambridge University Press. 
Axelrod, Robert. 2010. A Evolução da Cooperação. São Paulo: Leopardo.

Brasil. 2011. Decreto $n^{0}$ 7.496, de 8 de junho de 2011. Institui o Plano Estratégico de Fronteiras. Disponível em: <http://www.planalto.gov.br/ccivil_03/_ ato2011-2014/2011/decreto/d7496.htm>. Acesso em: 15 jan. 2016.

Ministério da Defesa. 2012a. Operações Interagências - MD33-M-12. Brasília. Disponível em: $<$ http://www.defesa.gov.br/arquivos/doutrina_militar/lista_de_publicacoes/md33_m_12_1_ed_

2012.pdf>. Acesso em: 10 jan. 2017.

Ministério da Defesa. 2012b. Doutrina de Operações Conjuntas - MD30-M-O1. Brasília. Disponível em: <http://www.defesa.gov.br/arquivos/legislacao/emcfa/publicacoes/doutrina/md30_m

_01_volume_1.pdf>. Acesso em: 10 dez. 2017.

Ministério da Defesa. 2015. Glossário das Forças Armadas - MD35-G-O1. Brasília. Disponível em: <http://www.defesa .gov.br/arquivos/legislacao/emcfa/ publicacoes/doutrina/md35_g

_01_glossario_das_forcas_armadas_5_ed_2015.pdf>. Acesso em: 10 dez. 2017.

2016. Decreto $n^{\circ} 8.903$, de 16 de novembro de 2016. Institui o Programa de Proteção Integrada de Fronteiras e organiza a atuação de unidades da administração pública federal para sua execução. Disponível em: <http://www.planalto. gov.br/ccivil_03/_Ato2015-2018/2016/Decreto/D8903.htm\#art9>. Acesso em: 10 jan. 2017.

Bressan, Sílvio. 2002. Reforma Administrativa. In Lamounier, Bolívar; Figueiredo, Rubens, A Era FHC: um Balanço. São Paulo: Cultura Editores Associados. 369-394.

Cepik, Marco A. 2001. Serviços de Inteligência: Agilidade e Transparência como Dilemas de Institucionalização. Tese de Doutorado em Ciência Política, Instituto Universitário de Pesquisas do Rio de Janeiro, Rio de Janeiro.

Drucker, Peter Ferdinand. 2001. Desafios Gerenciais para o Século XXI. São Paulo: Pioneira Thomson Learning.

Estados Unidos da América. Departamento de Defesa. 1996. Joint Publication 3-08 - Interagency, Intergovernmental Organization, and Nongovernmental Organization Coordination during Joint Operations. Washington. 
Departamento de Defesa. 2011. Joint Publication 3-08 - Interorganizational Coordination during Joint Operations. Washington.

. Departamento de Defesa. 2016. Joint Publication 3-08 - Interorganizational Cooperation. Washington.

Foucault, Michel. 2002. Vigiar e Punir: História da Violência nas Prisões. São Paulo: Ática.

Graça, Roberto Julian da Silva. 2015. As Operações Interagências no Combate ao Tráfico Internacional de Drogas: Contribuições da Operação Ágata 8. Monografia do Curso de Especialização em Ciências Militares, Escola de Comando e Estado-Maior do Exército, Rio de Janeiro.

Marcella, Gabriel. 2008. Understanding the Interagency Process: the Challenge of Adaptation”. In Marcella, Gabriel (Ed.), Affairs of State. The Interagency and National Security. Carlisle: Strategic Studies Institute. 1-52.

Raza, Salvador. 2012. Cooperação Interagências: Por Que e Como Funciona um Estudo de Modelos Organizacionais nas Relações Internacionais? Brazilian Journal of International Relations, 1, 1, 7-37.

Souza, Deywisson Ronaldo Oliveira de; Garcia, Stephanie Queiroz. 2014. A Abordagem Interagência dos Sistemas Proteger e de Monitoramento das Fronteiras Terrestres (SISFRON). Hegemonia, 14, 88-106.

Tribunal de Contas da União. 2015. Relatório de Auditoria Operacional TC 014.387/2014-O. Brasília. Disponível em: <http://portal.tcu.gov.br/lumis/portal/file/fileDownload.jsp?fileId=8A8182A24F99F 813014FB44FoDo50oF4\&inline=1>. Acesso em: 10 jan. 2017.

Tribunal de Contas da União. 2016. Relatório de Auditoria Operacional TC 020.053/2015-O. Brasília. Disponível em: <http://portal.tcu.gov.br/lumis/portal/file/fileDownload.jsp?fileId=8A8182A 1561E4260015652BB6C8E783A $>$. Acesso em: 10 jan. 2017. 


\section{NOTAS}

1. Publicação Conjunta 3-08.

2. Coordenação Interagências, Organizações Intergovernamentais, Organizações não Governamentais durante Operações Conjuntas.

3.Coordenação Interorganizacional durante Operações Conjuntas.

4. Cooperação Interorganizacional.

5. [...] organizações internacionais, agências de países estrangeiros, agências humanitárias públicas e privadas, e organizações religiosas $[\cdots]$.

6. […] coordenação interagências descreve a interação entre departamentos e agências do USG [Governo dos Estados Unidos] e é um subconjunto da cooperação interorganizacional. 


\section{MODELO BRASILEIRO DO AMBIENTE INTERAGÊNCIAS PARA OPERAÇÕES NA FRONTEIRA}

\section{RESUMO}

Esta pesquisa buscou identificar incongruências no âmbito do Plano Estratégico de Fronteiras, revelando dificuldades para estabelecer cooperação entre os partícipes de uma atividade interagências. Apesar das Operações Ágata e do Sistema Brasileiro de Inteligência, o Tribunal de Contas da União considera a inexistência de uma solução interagências no país.

Palavras-chave: Interagências; Fronteira; Segurança; Cooperação.

\section{ABSTRACT}

This research sought to identify inconsistencies within the scope of the Strategic Border Plan, revealing difficulties to establish cooperation among the participants in an interagency activity. Despite Ágata Operations and the Brazilian Intelligence System, the Brazilian Court of Audit considers the inexistence of an interagency solution in the country.

Keywords: Interagency; Border; Security; Cooperation. 